already arranged include lectures and discussions on theories of the photographic latent image, experimental work bearing on these theories, important properties of photographic materials, applications of photography to scientific research, and colour photography. Lectures will be given by Prof. N. F. Mott, Dr. W. F. Berg, Dr. J. C. M. Brentano, Dr. D. A. Spencer, Dr. E. R. Davies and Dr. S. O. Rawling. Full particulars will be announced at a later date.

\section{The Royal Institution}

ThE anniversary meeting of the members of the Royal Institution was held on May 1, during which the annual report of the visitors was received and adopted. Matters mentioned in the report included the appointment of Prof. W. L. Bragg, Cavendish professor of experimental physics at Cambridge, to succeed the late Lord Rutherford as professor of natural philosophy in the Institution, and of Prof. E. N. da C. Andrade to succeed Sir Henry Miers as chairman of the Library Committee. A legacy of $£ 1,000$, free of duty, has been received from the late Mr. P. A. Molteno, and the first payment has been made by the Asiatic Petroleum Co. Ltd. of an annual grant of $£ 100$ in aid of the researches at the Institution. The following officers were elected at the meeting : President, Lord Eustace Percy ; Treasurer, Sir Robert Robertson; Secretary, Major Charles E. S. Phillips.

\section{Recent Earthquakes}

Two earthquakes of considerable severity have been recorded by observatories in England recently. The first was recorded at Kew on April 21 at $4 \mathrm{~h}$. $39 \mathrm{~m} .56 \mathrm{~s}$. (dilatation) and the second on April 23 at $16 \mathrm{~h} .32 \mathrm{~m} .24 \mathrm{~s}$. G.C.T. The former is thought provisionally to have had an epicentre in northeastern Asia, and to have had a depth of focus of some $500 \mathrm{~km}$.; its occurrence is confirmed by a message from Dr. O. Somville of the Royal Observatory at Uccle, Belgium.

\section{Comet Jurlof-Achmarof-Hassel (1939 d)}

MUCH interest was shown in this comet, which was easily visible in field glasses, and it has been under observation since April 15, when it was discovered, until the present time. It had a tail about $4^{\circ}$ in length, but on April 22 this suddenly disappeared. Observers are certain that the tail was not diminishing in brightness an hour before its disappearance, and it is remarkable that it should have vanished so suddenly. It is receding from both earth and sun and so is diminishing in brightness; but it may be possible to find it with a small telescope until the middle of May. An ephemeris for a few dates is given below :

\begin{tabular}{|c|c|c|c|c|}
\hline \multirow{3}{*}{ May } & & \multirow{2}{*}{$\underset{5 \mathrm{~h} 46 \cdot 3 \mathrm{~m}}{\text { R.A. }}$} & \multicolumn{2}{|c|}{ N. Dec. } \\
\hline & 7 & & $32^{\circ}$ & 01 \\
\hline & 9 & $554 \cdot 8$ & 30 & 38 \\
\hline & 11 & $602 \cdot 1$ & 29 & 31 \\
\hline & 13 & $608 \cdot 3$ & 28 & 08 \\
\hline
\end{tabular}

Its distances from the earth and sun on May 9 are 116 and 78 million miles respectively.

\section{Announcements}

Prof. Fimile De Wildemann, professor of botany and agriculture in relation to the Belgian Congo in the Colonial University of Belgium, Anvers, has been elected correspondant for the Section of Botany of the Paris Academy of Sciences, in succession to the late Prof. V. Grégoire.

THE following officers of the North East Coast Institution of Engineers and Shipbuilders have recently been elected: President, Major T. Russell Cairns ; Vice-Presidents, Mr. Robert Haswell, Comdr. E. R. Micklem, Mr. H. B. Robin Rowell ; Honorary Treasurer, Mr. W. H. Pilmour; Secretary, Mr. T. S. Nicol.

THE Challenger Society for the Promotion of the Study of Oceanography will be making further grants in aid of research during the current year. The general committee is prepared to consider applications for small grants in aid of research in marine biology, the work preferably to be carried out at one of the recognized laboratories. Applications, accompanied by details of the proposed research, should reach the Honorary Secretary, Mr. J. R. Norman, British Museum (Natural History), S.W.7, before May 22.

IN compliance with the requirements of a gift under the will of the late Francis Amory, of Beverly, Massachusetts, the American Academy of Arts and Sciences announces the offer of a septennial prize. to be known as the Francis Amory Septennial Prize, for outstanding work with reference to the alleviation or cure of diseases affecting the human genital organs, If there is work of a quality to warrant it, the first award will be made in 1940. The total amount of the award will exceed ten thousand dollars, and may be given in one or more awards. Further information can be obtained from the Amory Fund Committee, c/o the American Academy of Arts and Sciences, 28 Newbury Street, Boston, Mass.

Catalogue 51, published by E. P. Goldschmidt and Co. of 45 Old Bond Street, London, W.1, includes a number of works illustrating the history of science and a few rare and important old medical books. The scientific works consist of first editions of books by Brahe, Copernicus, Galileo, Hutton, Huyghens, Kepler, Malpighi, Mendel, Newton and Pasteur, while the medical works are represented by first editions of Auenbrugger, Claude Bernard, Lister, Purkinje, Semmelweis and Steno. John Raphael Smith's oil portrait of Edward Jenner (1800) is also included, and modern but rare works such as the first edition of Freud's "Traumdeutung" (1900), Einstein's inaugural thesis (1905), Sir Charles Sherrington's "Integrative Action of the Nervous System" (1906), and Johannes Schmidt's "Con. tributions to the Life-History of the Eel" (1906). The catalogue is well illustrated and annotated. 